\title{
UNSTEADY FLOW SIMULATION AND COMBUSTION OF ETHANOL IN DIESEL ENGINES
}

The paper presents the survey of ethanol application as the fuel for diesel engines which is added to diesel fuel or injected to the inlet manifold. The paper describes unsteady flow simulation in the inlet manifold of a 4 cylinder diesel engine with injected ethanol (Martin Diesel UR $I V)$. The calculation of mixing rates is based on transient spray-plume-growth with concentration and temperature profile applying the CFD code (software of Fluent Inc. USA). The calculation of combustion was performed using a RNG $k-\varepsilon$ (renormalization group) turbulent model, standard wall function and a PDF model for chemical equilibrium of gas composition and kinetics in the combustion chamber.

Key words: diesel engines, combustion, ethanol, equilibrium and kinetic of gas composition

\section{Introduction}

The simulation of the processes concerning the combustion mixture creation has been for a long time period only at the level of an experimental matter. By means of the computer technology development and by application of differential methods the problems of the very consistent computational grids in the area of nozzle drills and in the locality where the combustion mixture is created at the fuel beam as well as the problems with enormous gradients of pressures, concentrations or velocities have been partly overcome. The aim of this work was to compare the exhaust emissions created at the combustion of ethanol mixed in diesel and ethanol injected in the intake manifold with the emissions originated by the combustion of pure diesel fuel. The simulation was done for the ethanol injection into the intake channel of the engine head of the Martin Diesel UR IV engine and at the combustion process specified for a compression ignition engine at the consideration of the equilibrium composition of emissions and kinetics of combustion of ethanol. For simulated calculation the equations of continuity, Navier - Stokes equations, equations for energy balance and Arrhenius rate equation were applied.

\section{Applied numerical method}

For formation of the combustion mixture the following basic balance equations can be applied.

The continuity equation for the component $\alpha$ :

$$
\frac{\partial \theta \rho_{\alpha}}{\partial t}+\nabla \cdot\left(\theta \rho_{\alpha} \vec{u}\right)=\nabla \cdot \theta \rho D \nabla \frac{\rho_{\alpha}}{\rho}+\left(\dot{\rho}_{\alpha}\right)_{p}
$$

where: $\theta$ represents the volume portion taken by gas,

$\left(\rho_{\alpha}\right)_{p}$ describes the velocity of density change of the $\alpha$ component caused by evaporation.

For individual particles

$$
\left(\dot{\rho}_{\alpha}\right)_{p}=0, \quad \alpha \neq v \quad\left(\dot{\rho}_{v}\right)_{p}=-\frac{1}{V} \sum_{k} \frac{d m_{k}}{d t},
$$

where the element $\mathrm{v}$ represents evaporated fuel, $V$ is volume throughout all the particles and $m_{k}$ stands for the mass of $k$-particle.

Then the equation for the momentum compliance can be written in the form:

$$
\begin{aligned}
& \frac{\partial \theta \rho \vec{u}}{\partial t}+\nabla \cdot(\theta \rho \vec{u} \vec{u})=-\theta \nabla p+\nabla \cdot \\
& \cdot \theta(\mu \overleftrightarrow{e}+\lambda \overleftrightarrow{I} \nabla \cdot \vec{u})-\frac{1}{V} \sum_{k} D_{k}\left(\vec{u}-\vec{u}_{p k}\right)
\end{aligned}
$$

where: $u_{p k}$ represents the velocity of k-particle, $D_{k}$ is the function of the particle carrying, $e$ is tensor of viscosity tension and $\bar{I}$ stand for the unit tensor.

For Stokes' streaming round the drop

$$
D_{k}=6 \pi \mu r_{k}+\frac{1}{2} \pi r_{k}^{2} \rho C_{D}\left|\vec{u}-\vec{u}_{p k}\right|
$$

where $r_{k}$ is the particle semi-diameter and $C_{D}$ coefficient of particle drag.

The equation of the inner energy $I$ :

\footnotetext{
* Ján Lábaj, Dalibor Barta

University of Zilina, Univerzitná 1, 01026 Žilina, Slovak Republic,

E-mail: jan.labaj@fstroj.utc.sk, dalibor.barta@fstroj.utc.sk
} 


$$
\begin{aligned}
& \theta \rho\left[\frac{\partial I}{\partial t}+\vec{u} \cdot \nabla I\right]=\frac{\theta p}{\rho}\left[\frac{\partial \rho}{\partial t}+\vec{u} \cdot \nabla \rho\right]+\nabla \cdot \theta\left[K \nabla \mathrm{T}+\rho D \sum_{\alpha} h_{\alpha} \nabla \frac{\rho_{\alpha}}{\rho}\right]+\theta\left[\frac{\mu}{2} \overleftrightarrow{e}: \overleftrightarrow{e}+\lambda(\nabla \cdot \vec{u})^{2}\right]+ \\
& +\frac{1}{V} \sum_{k}\left[\left(D_{k}-\frac{1}{2} \frac{d m_{k}}{d t}\right)\left|\vec{u}-u_{p k}\right|-q_{k}+\left(h-h_{v}\right) \frac{d m_{k}}{d t}\right]
\end{aligned}
$$

where. $q_{k}$ represents the intensity of thermal transfer from gas into the k-particle,

$h_{\alpha}$ is specific enthalpy of $\alpha$ component,

$h$ - total enthalpy,

$\mu, \lambda$ - first and second viscosity coefficients.

The equations are solved by means of the finite volume method as follows:

$$
\begin{aligned}
& \frac{d}{d t} \int_{V} \rho_{\alpha} d V-\int_{S} \rho_{\alpha}\left(\vec{u}_{g}-\vec{u}\right) \cdot \vec{n} d S=\int_{S}\left(\rho D \nabla \frac{\rho_{\alpha}}{\rho}\right) \cdot \\
& \cdot \vec{n} d S+\int_{V}\left(\dot{\rho}_{\alpha}\right)_{c} d V \\
& \frac{d}{d t} \int_{V} \rho \vec{u} d V-\int_{S} \rho \vec{u}\left(\vec{u}_{g}-\vec{u}\right) \cdot \vec{n} d S=-\int_{S} \rho \vec{n} d S+ \\
& +\int_{S}(\mu \vec{e}+\lambda \vec{I} \nabla \cdot \vec{u}) \cdot \vec{n} d S \\
& \frac{d}{d t} \rho I d V-\int_{S} \rho I\left(\vec{u}_{g}-\vec{u}\right) \cdot \vec{n} d S+\int_{V} \rho \nabla \cdot \vec{u} d V= \\
& \int_{S}(K \nabla T) \cdot \vec{n} d S+\int_{V}\left(\frac{\mu}{2} \vec{e}: \vec{e}+\lambda(\nabla \cdot \vec{u}) 2+\dot{Q}_{c}\right) d V
\end{aligned}
$$

where: $V$ is volume, $S$ surface and $n$ - normal line.

\section{PDF model}

The composition of exhaust gas was calculated as equilibrium by searching the minimum of the system free enthalpy. To proceed from the assumption of high temperatures where the diffusion and mixture formation represent slower processes compared to chemical kinetics and, therefore, play the predominant role for exhaust gas formation. On the basis of this idea the calculation was done for diffusion flame in a high turbulent regime respecting the probability density function PDF. This function written as $p(f)$ describes a time interval of the fluctuation variable $f$, which is in the interval $f+\Delta f$. Then, the values within the time interval are calculated as $\Delta$ f.p(f). The mathematical formula can be written as follows:

$$
p(f) \Delta f=\lim _{T \rightarrow \infty} \frac{1}{T} \sum_{i} \tau_{i},
$$

where: $\tau_{i}$ represents the time interval when the function $f$ is in the extent of $\Delta f$. The form of the function $p(f)$ depends on the natural turbulence fluctuations within $f$., $p(f)$ is expressed as a mathematical function PDF whose form is derived from the experiment.

The probability density function $p(f)$ describes the transient fluctuations of the turbulent stream and for its definition the time depended average values are used. In such a way the time depended

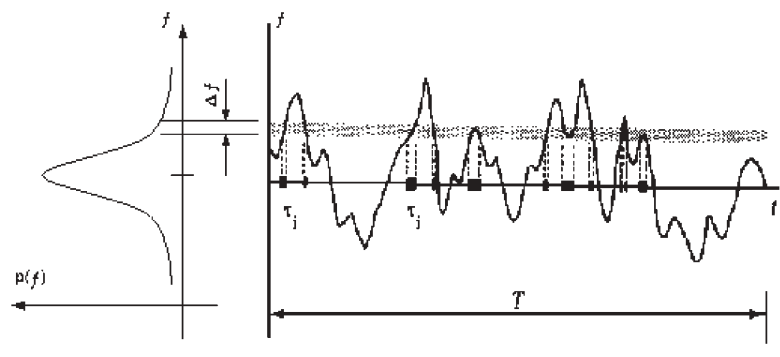

Fig. 1 Graphical illustration of the probability density function $p(f)$

average value for exhaust component concentration and temperature can be formulated in the form

$$
\bar{\Phi}_{i}=\int_{0}^{1} p(f) \Phi_{i}(f) d f
$$

for one individual fraction of the system. Concerning also the secondary stream the average value can be calculated using the following equation:

$$
\bar{\Phi}_{i}=\int_{0}^{1} \int_{0}^{1} p_{1}\left(f_{\text {fuel }}\right) p_{2}\left(p_{\text {secondary }}\right) \Phi_{i}\left(f_{\text {fuel }}, p_{\text {secondary }}\right) d f_{\text {fuel }} d p_{\text {secondary }}
$$

where: $p_{1}$ is PDF for $f_{\text {fuel }}$ and $p_{2}$ PDF for $p_{\text {secondary }}$

Similarly, also the time related average value of liquid density can be calculated only for one mixture

$$
\frac{1}{\bar{\rho}}=\int_{0}^{1} \frac{p(f)}{\rho(f)} d f
$$

when two different streams come into the system, then:

$$
\frac{1}{\bar{\rho}}=\int_{0}^{1} \int_{0}^{1} \frac{p_{1}\left(f_{\text {fuel }}\right) p_{2}\left(p_{\text {secondary }}\right)}{\rho\left(f_{\text {fuel }}\right),\left(p_{\text {secondary }}\right)} d f_{\text {fuel }} d p_{\text {secondary }}
$$

when for the secondary stream $\rho(f)$ or $\rho\left(f_{\text {fuel }}, p_{\text {secondary. }}\right)$ exists.

The selection of the function (e.g. Gauss function) can be provided on the basis of experimental measurements of fluctuations.

The double delta function can be written in the form:

$$
p(f)=\left\{\begin{array}{cr}
0.5, & f=\bar{f}-\sqrt{\bar{f}^{\prime 2}} \\
0.5, & f=\bar{f}+\sqrt{\bar{f}^{\prime 2}} \\
0, & \text { elsewhere }
\end{array}\right.
$$

Then the calculation of the double delta function is not complicated and can be made more precise than the alternative $\beta$ PDF function. 


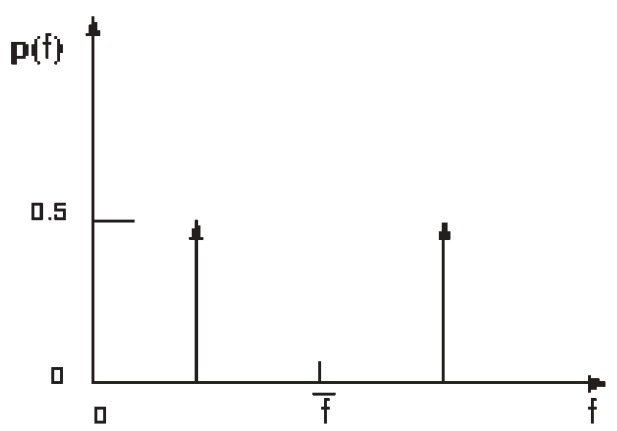

Fig. 2 Double delta function in the PDF form

The $\beta$ function in PDF form can be expressed in the following version:

$$
p(f)=\frac{f^{\alpha-1}(1-f)^{\beta-1}}{\int f^{\alpha-1}(1-f)^{\beta-1} \alpha f},
$$

where $\quad \alpha=\bar{f}\left[\frac{\bar{f}(1-\bar{f})}{\bar{f}^{\prime 2}}-1\right]$

and also $\beta=(1-\bar{f})\left[\frac{\bar{f}(1-\bar{f})}{\bar{f}^{\prime 2}}-1\right]$.

From the created tables the program at the calculation will read the values of temperatures and concentrations for multi-stream turbulent streaming and at mixing of streams which chemically react.

A non-adiabatic PDF model of combustion calculates the total enthalpy from the energy equilibrium equation:

$$
\frac{\partial}{\partial t}(\rho H)+\frac{\partial}{\partial x_{i}}\left(\rho u_{i} H\right)=\frac{\partial}{\partial x_{i}}\left(\frac{k_{t}}{c_{p}} \frac{\partial H}{\partial x_{i}}\right)+\tau_{i k} \frac{\partial u_{i}}{\partial x_{k}}+S h \text {. }
$$

The solution is possible when the Lewis number $=1$. The total enthalpy

$$
H=\sum_{j} m_{j} H_{j}
$$

where $m_{j}$ is a mass portion of $j$ component and $H_{j}$

$$
H_{j}=\int_{T_{r e f, j}}^{T} c_{p, j} d T+h_{j}^{0}\left(T_{r e f, j}\right),
$$

where $h_{j}^{0}$ is a compound enthalpy of $j$-component at the temperature of $T_{r e f}$.

\section{A virtual model of the intake channel and combustion chamber}

The task of a model creation for the mixture formation represents one of the complicated problems in the field of gas dynamics, and from this point of view it is necessary to make some simplifications and to select and apply the existing sub-models for turbulent streaming, drop distribution or boundary layer. The task was solved in two stages. Separately the ethanol injection in the intake channel for the engine Martin Diesel URIV (4 cylinders in line, turbo-charged) and separately the combustion of ethanol mixed in a diesel as the combustion of air / ethanol mixture ignited by injection of pure diesel. At the task solving the method CFD (Computational Fluid Dynamic) was applied. For the calculation of drop evaporation the professional programs offer the distribution curve by software. The calculation of the combustion mixture formation can be provided on the basis of the published empirical relations or by detailed mathematical models, but in this case the most sophisticated computer technology is required.

\section{Initial and boundary conditions for calculation}

The fuel injection was realised by one-point injection in the intake channel. The surface grid of the intake channel and valve (in an open position) is illustrated in Fig. 3. The apparent intake pressure by a turbo-blower is $0.08 \mathrm{MPa}$, the intake air temperature $120{ }^{\circ} \mathrm{C}$. For the ethanol injection the piston movement was simulated by a boundary condition as the velocity of gas movement out from the cylinder or in the opposite way which was adequate for a suction stroke at $2200 \mathrm{rpm}$. in the range of TDC up to $40^{\circ} \mathrm{CA}$ after BDC when the intake valve closes. The task was solved as not-stationary. The temperature of the intake channel was $80^{\circ} \mathrm{C}$, the calculation interval $10 \mathrm{deg}$. CA. The fuel injection was realised during the whole suction stroke. For drop evaporation the stochastic model was applied, for streaming the model for turbulence RNG $k-\varepsilon$, standard grid function. At the calculation in the FLUENT 5 programme the Rosin-Rammler distribution function was applied, which is in this programme pre-defined.

For the combustion process simulation the back-pressure was simulated with the values of real measured combustion pressure at the combustion of pure diesel. The surface grid of combustion chamber without the engine head grid is presented in Fig. 4, the grid of the part of injection nozzle which reached the combustion chamber in Fig. 5, the grid of injection nozzle drills in Fig. 6. The fuel injection began at $10^{\circ}$ BTDC and in the case of pure diesel the injection ended at $11^{\circ}$ ATDC. The calculation was made with the interval of $2^{\circ} \mathrm{CA}$ for all the three cases. At the combustion simulation of the ethanol / air mixture the injection timing was reduced to $1 / 4$ with the identical injection beginning. With the purpose of a model simplification the diesel fuel was substituted by a fictive hydrocarbon $\mathrm{C}_{16} \mathrm{H}_{29}$. The injector drill diameter $d=0.27 \mathrm{~mm}$. The temperature of injected fuel $T_{p}=423 \mathrm{~K}$. The fuel rate of flow through one injection drill $Q_{p}=11.10^{-6} \mathrm{~kg} . \mathrm{s}^{-1}$. The interval of injection timing $21^{\circ} \mathrm{CA}$. The wall temperature in the combustion chamber $T_{s}=700 \mathrm{~K}$. The velocity of fuel flow through the injection drill $v_{p}=180 \mathrm{~m} \cdot \mathrm{s}^{-1}$.

For more precise calculation it was convenient to apply a kinetic model with the detailed description of ethanol transformation through the intermediate products in $\mathrm{CO}$ and subsequently in $\mathrm{CO}_{2}$. Through this model it would be possible to simulate the formation of aldehydes and unburned hydrocarbons at the diesel fuel combustion. Such a model was prepared but due to the insufficient computer parameters only the simulation of the mixture formation in 


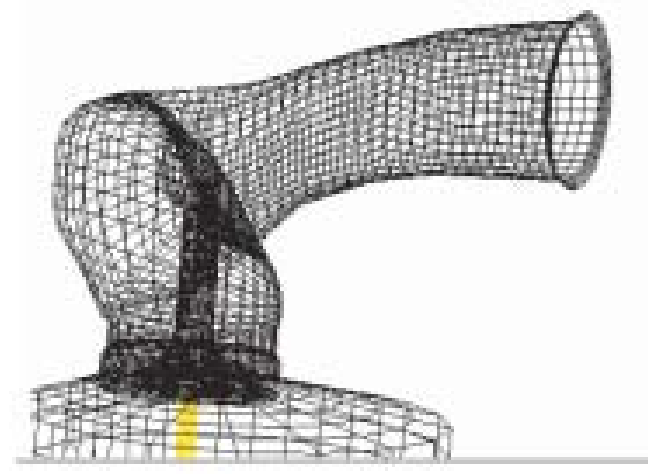

Fig. 3 Surface grid of intake channel

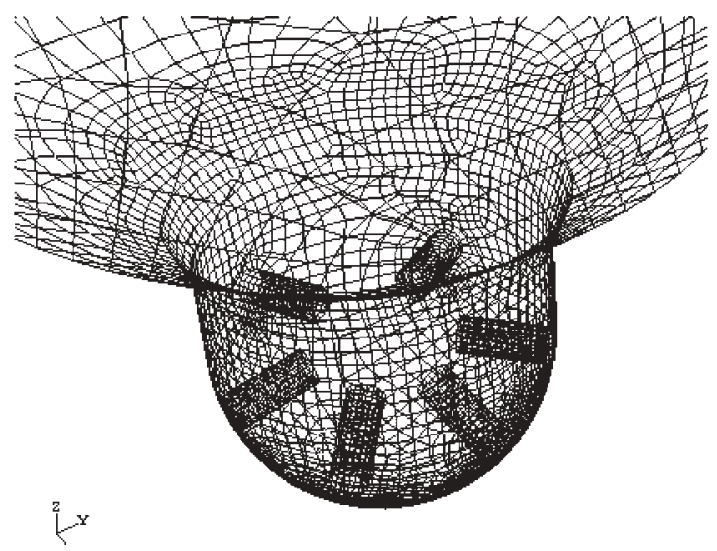

Fig. 5 Surface grid of injection nozzle

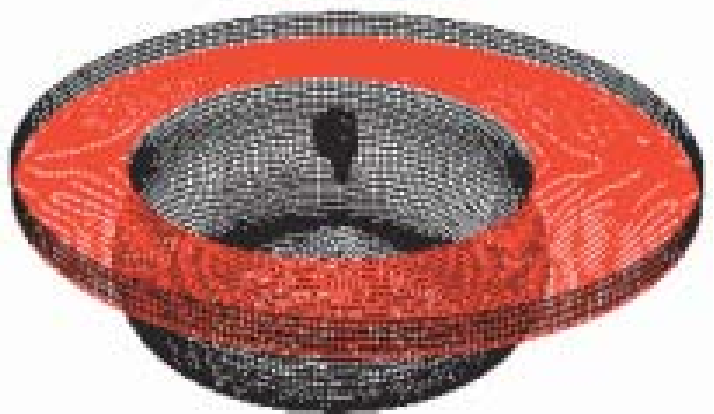

Fig. 4 Surface grid of combustion chamber without the engine head grid

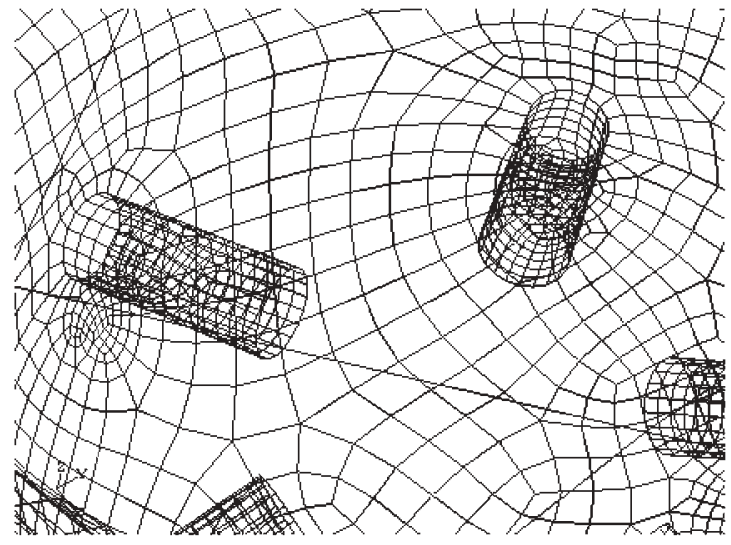

Fig. 6 Surface grid of injection nozzle drills the combustion chamber was realised. The figures illustrate the exhaust emission concentration at $10^{\circ} \mathrm{CA}$ ATDC (in the point of the maximal combustion pressure).

\section{Figures of the simulated velocity and temperature fields}

Figs. 7 - 9 illustrate the ethanol concentration in the boundary layer in the intake channel vs. the angle of crankshaft. Figs. 10 - 13 present the cooling effect of injected ethanol. At the end of the suction stroke the temperature increase can be observed. It is caused by heating-up from the walls and by dynamics of the suctioned mixture.

Due to different specific caloric values (pure diesel vs. diesel / ethanol mixture) also the difference in the combustion chamber can be observed (illustrated in Figs. 13 and 14).

At the application of ethanol in diesel the increased temperature in the location of nozzle drill can be observed which can cause a higher temperature of the injection nozzle. The higher cylinder loading caused by cooling of the suctioned mixture results in the increase of temperature in the combustion chamber. The ignition portion represented $1 / 4$ from the total fuel portion at the maximal engine power, e.g. $1 / 4$ from the injection timing at the identical injection pressure. Fig. 15 illustrates static temperature, this figure must be assessed together with the Fig. 27 in which the curves of the constant velocity (iso-tacheo-curves) of combustion mixture streaming are presented. From this reason in Fig. 15 no change of temperature at the injection nozzle drill is evident, the fuel injection was finished before the timing point of $10^{\circ}$ after TDC. Figs. 16 and 17 document the decrease of $\mathrm{CO}$ concentration comparing to the operation with pure diesel. Ethanol has a lower theoretical air consumption than diesel and at the identical fuel portion the engine operating with ethanol shows a higher air surplus. At the combustion of ethanol ignited by diesel (25\%) the higher concentration of $\mathrm{CO}$ at the combustion chamber walls and also in average occurs (Fig. 18). The identical effect could be observed as for the unburned hydrocarbons concentration due to the extinguish effect at the combustion chamber walls.

The similar behaviour can be observed also for nitrogen oxide concentration. When the engine operates at lean combustion mixture, through the addition of ethanol into the fuel the NO concentration in combustion chamber will be decreased (Figs. 19 and 20). 


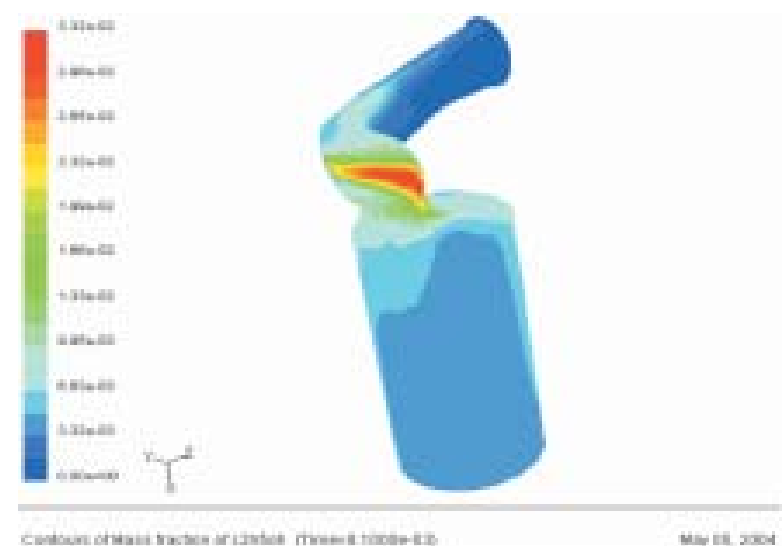

Fig. 7 Mass fraction number of ethanol $72^{\circ} \mathrm{CA}$ after TDC

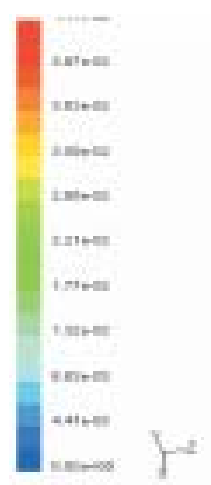

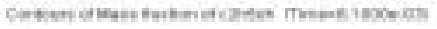

Fig. 8 Mass fraction number of ethanol $108^{\circ} \mathrm{CA}$ after TDC
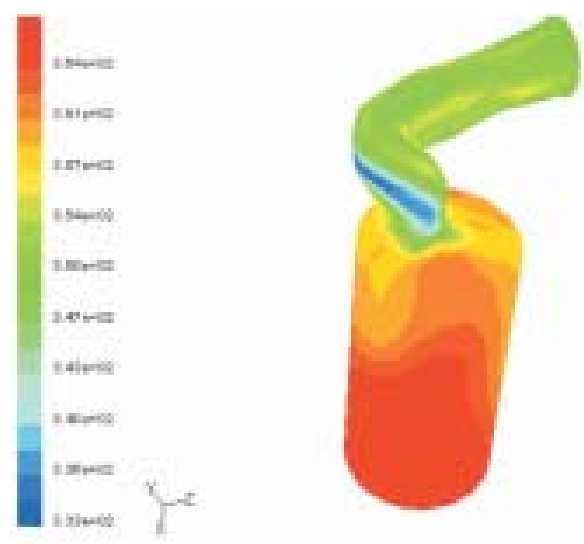

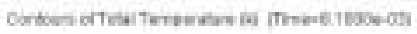

un os, ane

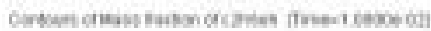

misting

Fig. 9 Mass fraction number of ethanol $144^{\circ} \mathrm{CA}$ after TDC
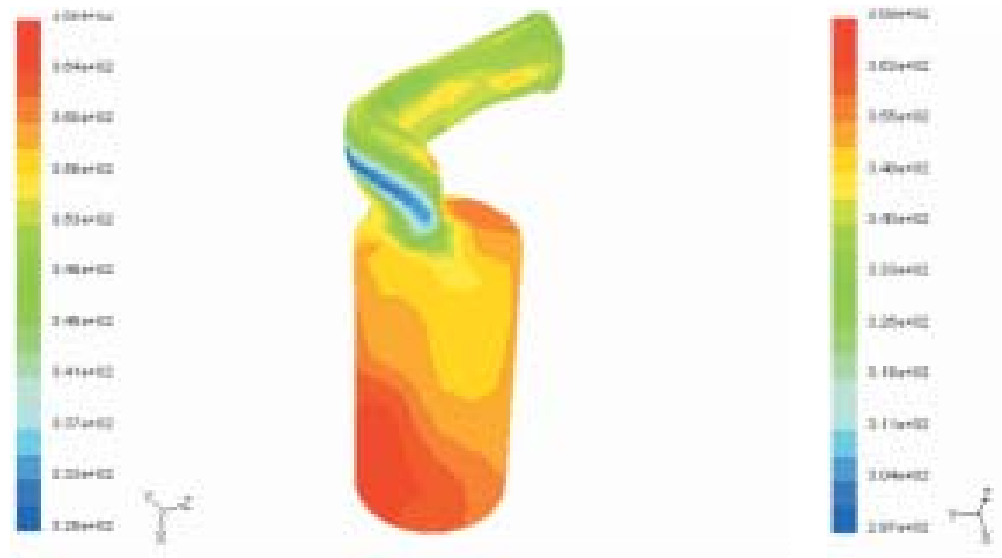

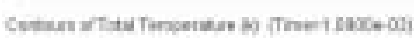

mow is 2304

Fig. 11 Temperature (K) $108^{\circ}$ CA after TDC

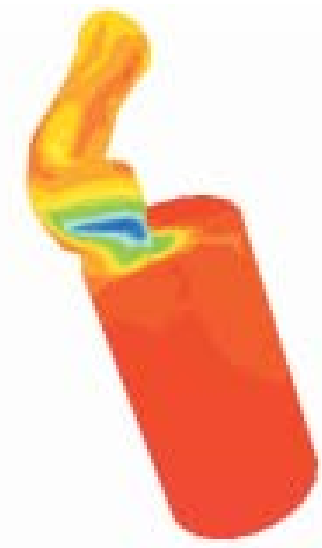

Fig. 10 Temperature (K) $72^{\circ} \mathrm{CA}$ after $T D C$

Fig. 12 Temperature (K) $144^{\circ} \mathrm{CA}$ after TDC 


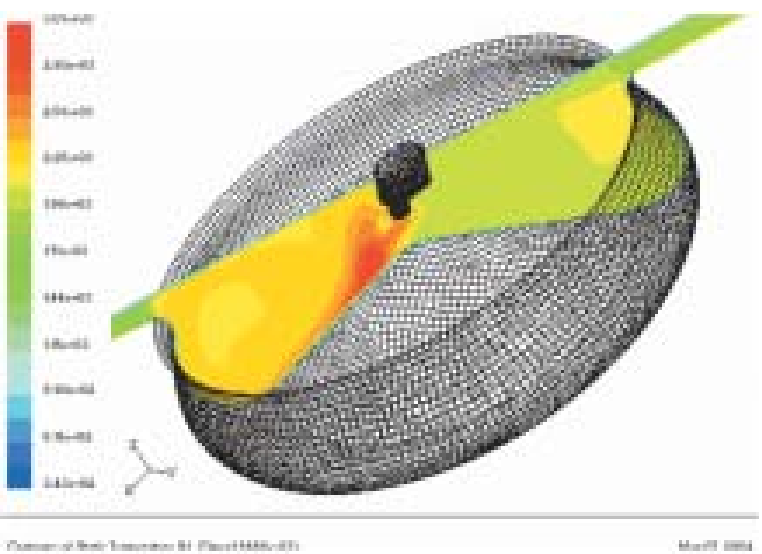

Fig. 13 Static temperature (K) $10^{\circ} \mathrm{CA}$ after TDC, fuel: $\mathrm{C}_{16} \mathrm{H}_{29}$. Average temperature in combustion chamber $=2100 \mathrm{~K}$

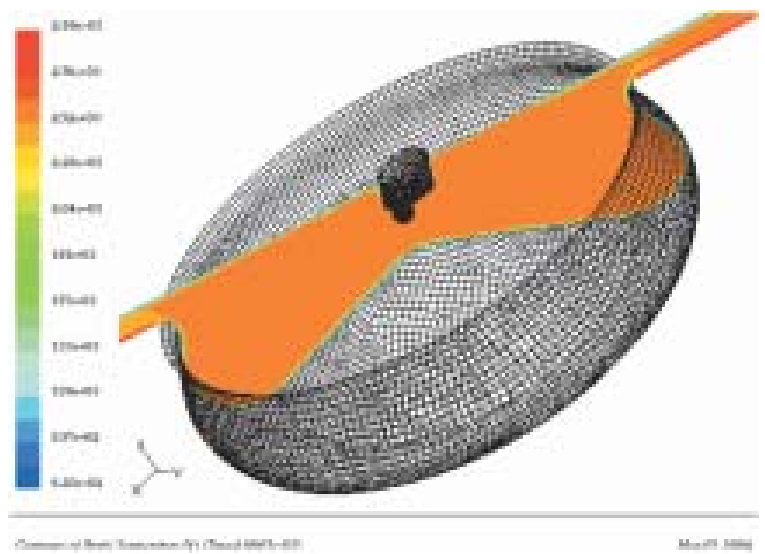

Fig. 15 Static temperature (K) $10^{\circ} \mathrm{CA}$ after TDC, fuel: ethanol / air mixture, ignition portion $25 \%$ of the total energy content, identical heat input as at pure diesel $T=2550 \mathrm{~K}$

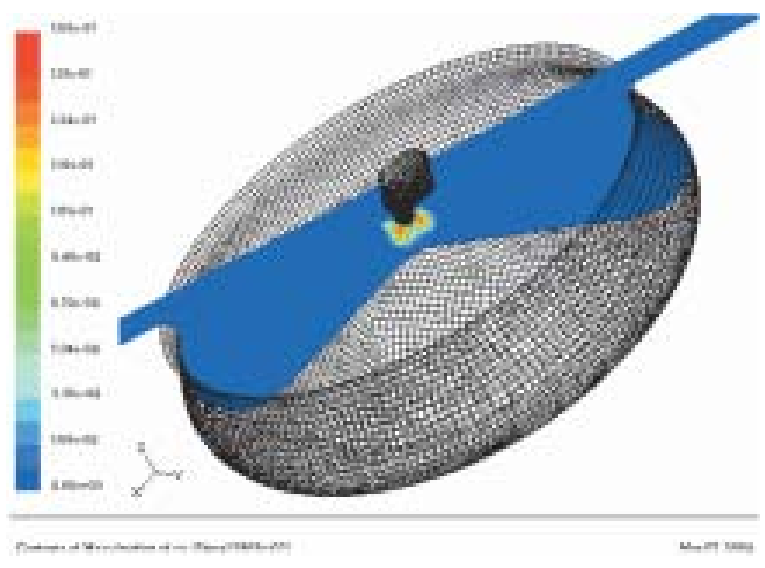

Fig. 17 Mass fraction number of $\mathrm{CO} 0^{\circ} \mathrm{CA}$ after TDC, identical fuel portion as at diesel operation, fuel: $20 \%$ ethanol in $\mathrm{C}_{16} \mathrm{H}_{29}$. Average concentration of $\mathrm{CO}$ (mass fraction number) in combustion chamber $=0.001433$

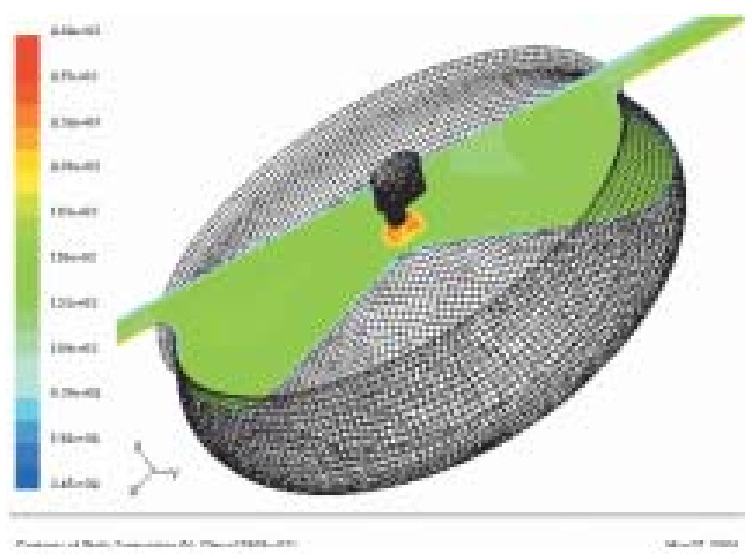

Fig. 14 Static temperature (K) $10^{\circ} \mathrm{CA}$ after TDC, identical fuel mass injection comparing to pure diesel fuel: $20 \%$ ethanol in $\mathrm{C}_{16} \mathrm{H}_{29}$. Average temperature in combustion chamber $=1500 \mathrm{~K}$

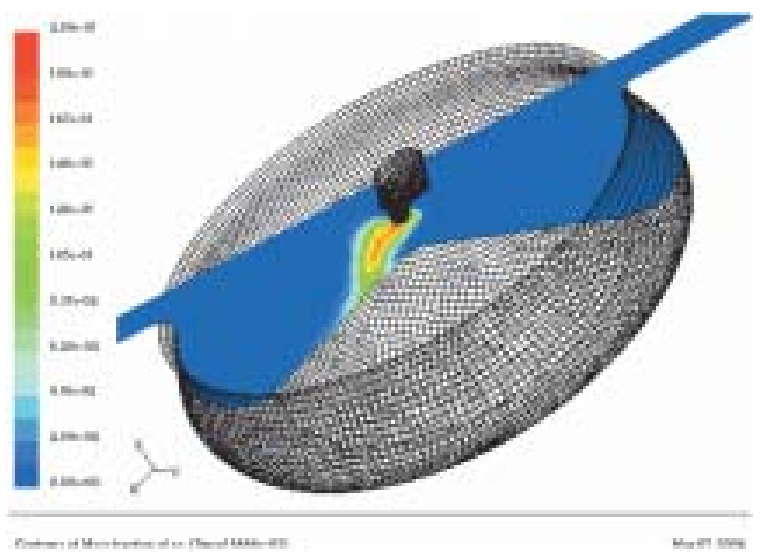

Fig. 16 Mass fraction number of $\mathrm{CO} 10^{\circ} \mathrm{CA}$ after TDC, fuel: $\mathrm{C}_{16} \mathrm{H}_{29}$, Average concentration of $\mathrm{CO}$ (mass fraction number) in combustion chamber $=0.002936$

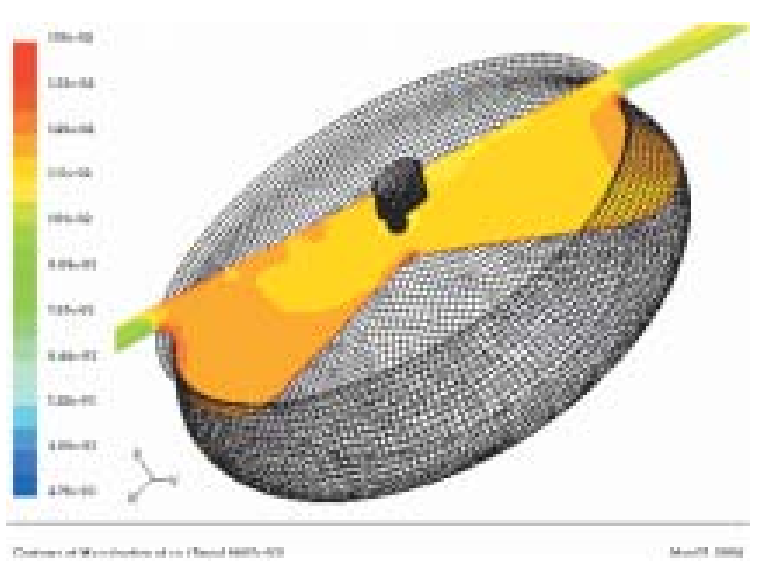

Fig. 18 Mass fraction number of $\mathrm{CO} 10^{\circ} \mathrm{CA}$ after TDC, fuel: ethanol with air ignition portion $25 \%$ of total energy content, identical heat input as at diesel operation. Average concentration of $\mathrm{CO}$ (mass fraction number) in combustion chamber $=0.01176$ 


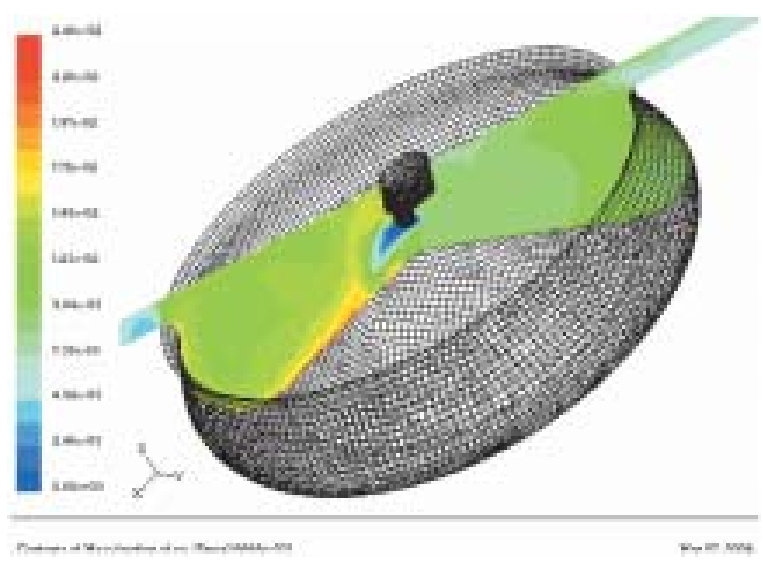

Fig. 19 Mass fraction number of $\mathrm{NO} 10^{\circ} \mathrm{CA}$ after TDC, fuel: $\mathrm{C}_{16} \mathrm{H}_{29}$, Average NO concentration (mass fraction number) in combustion chamber $=0.01046$

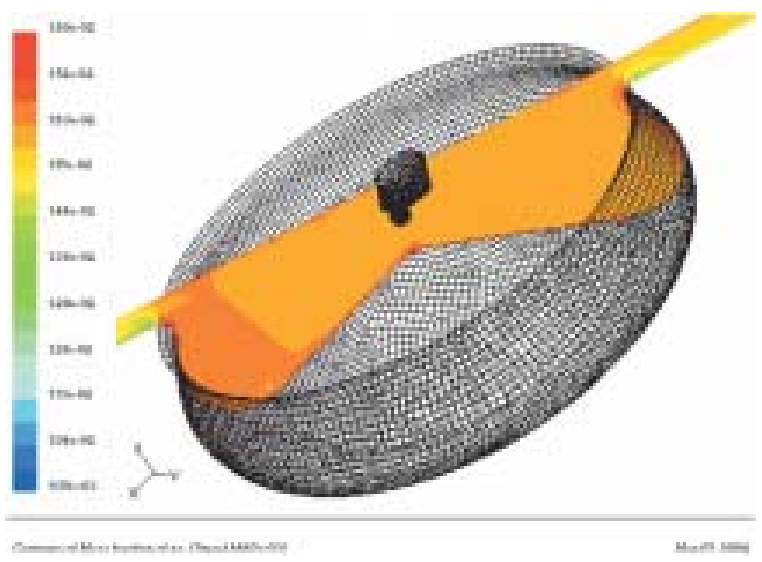

Fig. 21 Mass fraction number of NO $10^{\circ} \mathrm{CA}$ after TDC, fuel: ethanol with air, ignition portion $25 \%$ of total energy content, identical heat input as at diesel operation. Average NO concentration (mass fraction number) in combustion chamber $=0.01615$

In the case that the engine operates at the same power output with the ethanol injection in the suction channel through the higher charging by combustion mixture the NO concentration will be increased (Fig. 21). The NO concentration is kinetically retarded during the power stroke at its maximal value.

Equilibrium concentrations of $\mathrm{NO}_{2}$ in the combustion chamber are very low, the concentration of NO is predominant, while the transformation of $\mathrm{NO}$ into $\mathrm{NO}_{2}$ takes place in the exhaust system and then in the atmosphere. The $\mathrm{NO}_{2}$ concentration depends on the temperature and oxygen content in the beam of injected fuel.

Figs. 25 - 27 illustrate the iso-tacheo-curves in the combustion chamber which document the change in combustion process when ethanol is applied in diesel fuel or injected in the suction manifold.

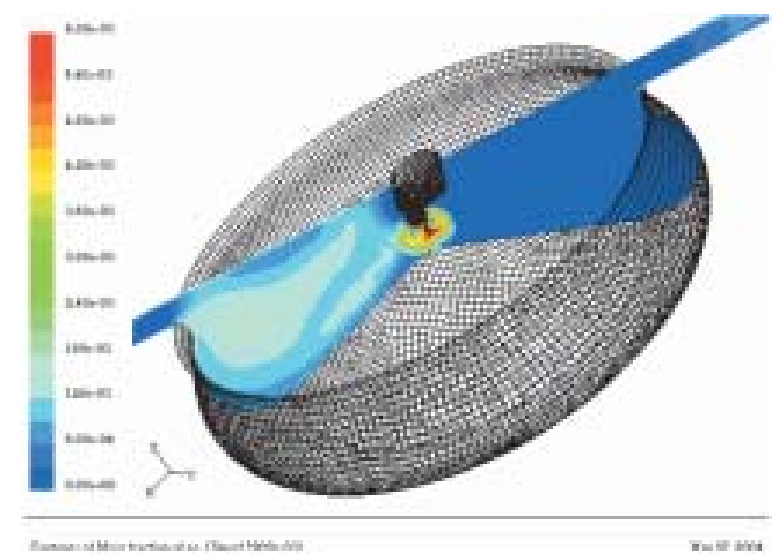

Fig. 20 Mass fraction number of NO $10^{\circ} \mathrm{CA}$ after TDC, fuel: $20 \%$ ethanol in $C_{16} H_{29}$ identical fuel portion as at diesel operation. Average NO concentration (mass fraction number) in combustion chamber $=0.01033$

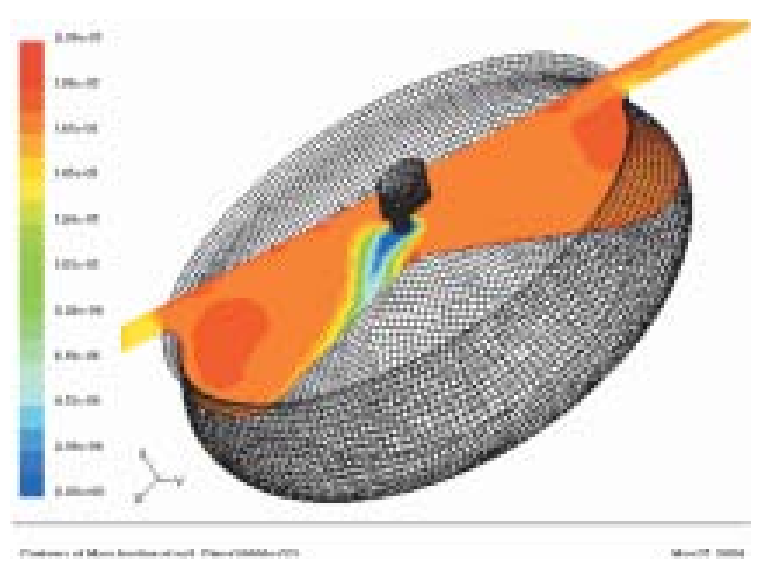

Fig. 22 Mass fraction number of NO2 $10^{\circ} \mathrm{CA}$ after TDC, fuel: $\mathrm{C}_{16} \mathrm{H}_{29}$. Average $\mathrm{NO}_{2}$ concentration (mass fraction number) in combustion chamber $=1.6848 e-5$

The figures presented not only the changes of local velocity but also the modification of the whole velocity field. The high average velocity shown in Fig. 27 can be considered as the result of fictive combustion process in the whole combustion chamber at the calculating model based on the equilibrium state of exhaust gas composition.

\section{Combustion simulation of ethanol in a diesel engine - kinetic model}

The final part of paper shows kinetic combustion of ethanol with CFD method in combustion chamber of diesel engine. The coefficients for a kinetic model are from Fluent. Inc. database (Tab 1). 


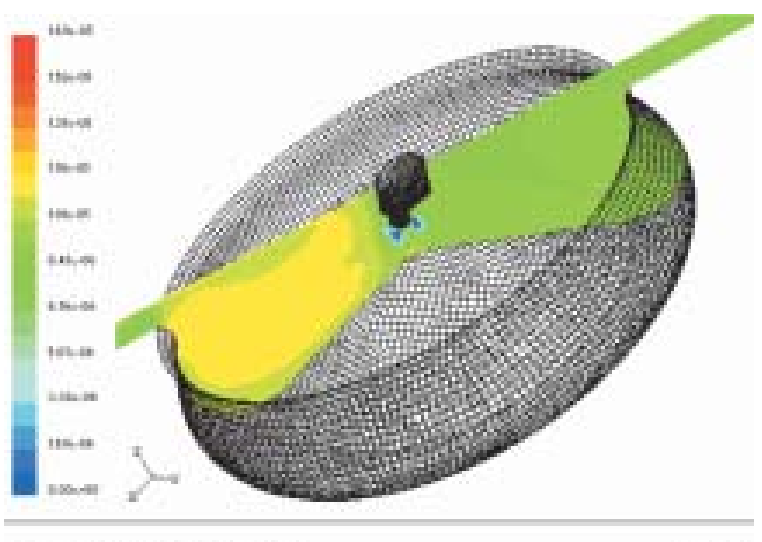

Fig. 23 Mass fraction number of NO2 $10^{\circ} \mathrm{CA}$ after TDC, fuel: $20 \%$ ethanol in $\mathrm{C}_{16} \mathrm{H}_{29}$ identical fuel portion as at diesel operation. Average $\mathrm{NO}_{2}$ concentration (mass fraction number) in combustion chamber $=1.0078 \mathrm{e}-5$

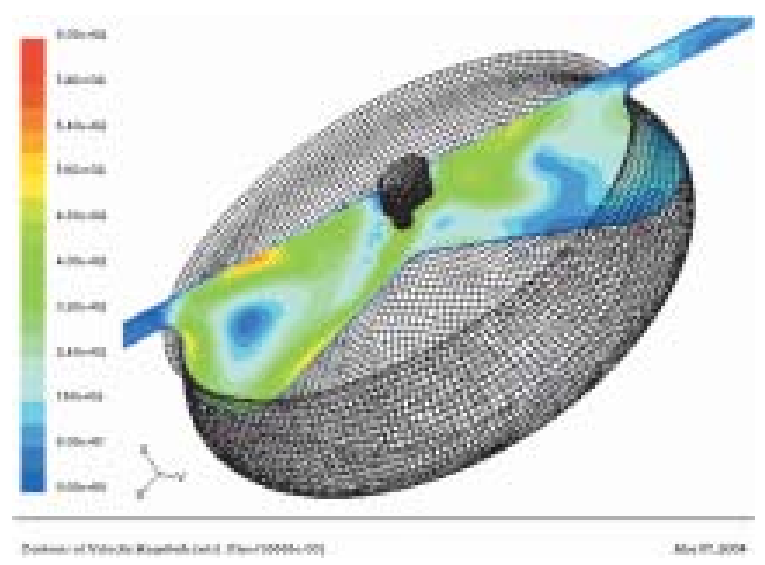

Fig. 25 Iso-tacheo-curves $10^{\circ} \mathrm{CA}$ after TDC, fuel: $\mathrm{C}_{16} \mathrm{H}_{29}$. Average velocity of burned mixture in combustion chamber $=231 \mathrm{~m} / \mathrm{s}$

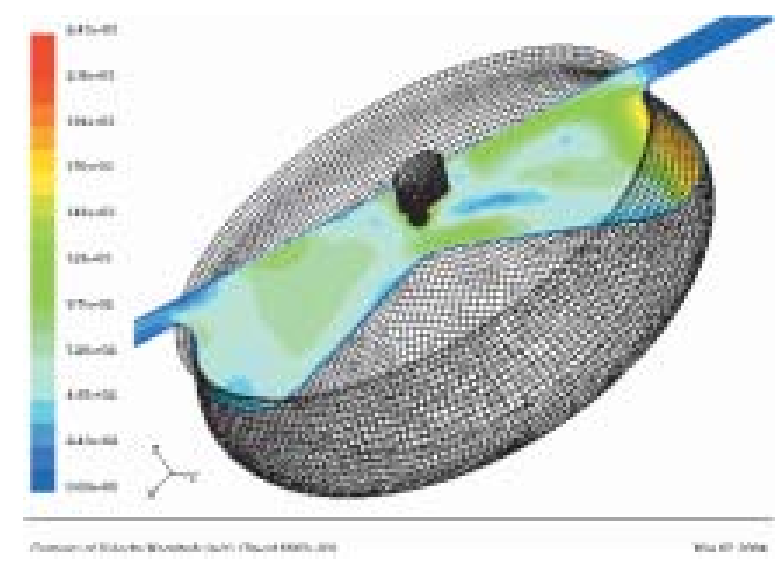

Fig. 27 Iso-tacheo-curves $10^{\circ} \mathrm{CA}$ after TDC, fuel: ethanol with air ignition portion $25 \%$ of total energy content identical heat input as at diesel operation. Average velocity of burned mixture in combustion chamber $=675 \mathrm{~m} / \mathrm{s}$

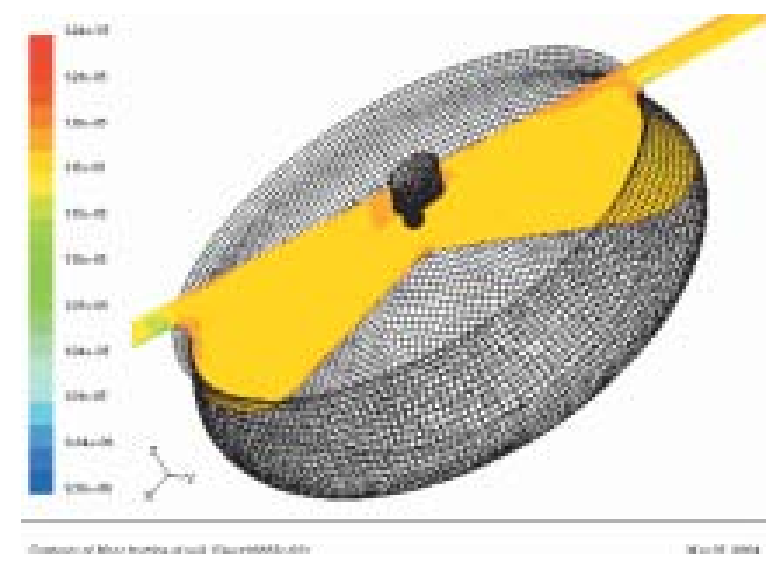

Fig. 24 Mass fraction number of NO2 $10^{\circ} \mathrm{CA}$ after TDC, fuel: ethanol with air ignition portion $25 \%$ of total energy content. Identical heat input as at diesel operation. Average $\mathrm{NO}_{2}$ concentration (mass fraction number) in combustion chamber $=1.1652 e-5$

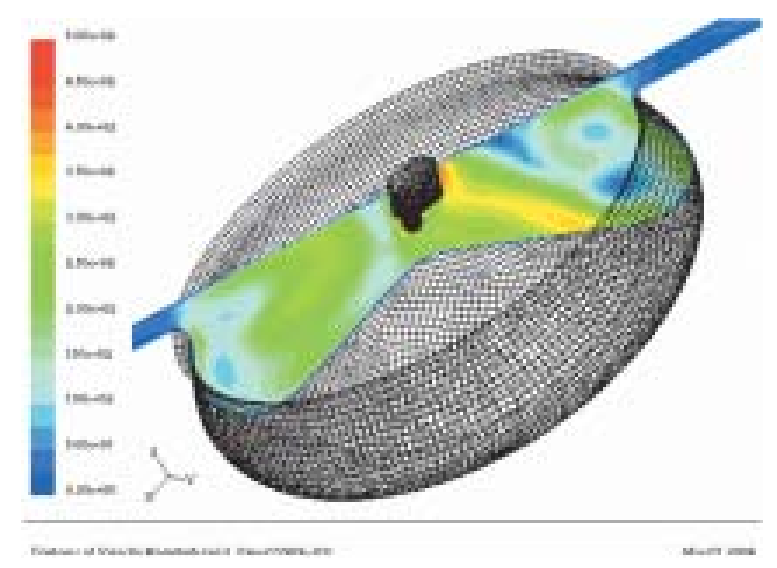

Fig. 26 Iso-tacheo-curves $10^{\circ} \mathrm{CA}$ after TDC, fuel: $20 \%$ ethanol in $C_{16}$ $\mathrm{H}_{29}$ identical fuel portion as at diesel operation. Average velocity of burned mixture in combustion chamber $=163 \mathrm{~m} / \mathrm{s}$

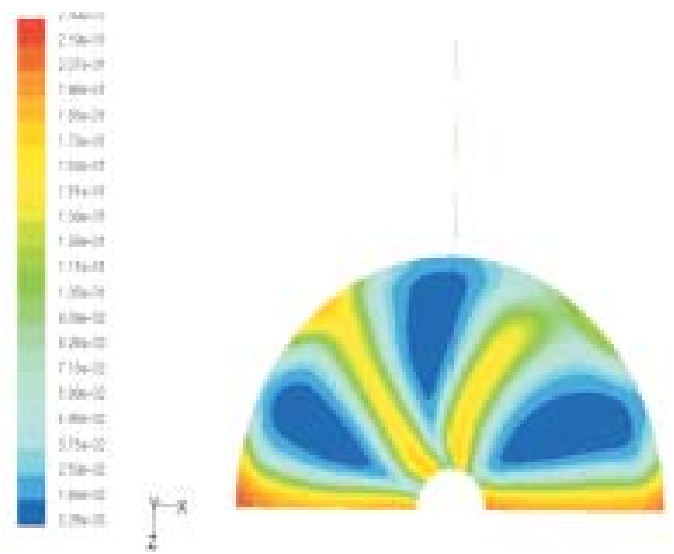

Fig. 28 Tangential flow at top dead center to plane of injection orifice (mass fraction of oxygen for kinetic model) 
Coefficients for kinetics of combustion of ethanol

\begin{tabular}{|l|c|c|}
\hline Species & Stechiometric. coef. $v$ & Rate exponent $\eta$ \\
\hline $\mathrm{C}_{2} \mathrm{H}_{5} \mathrm{OH}$ & 1 & 0,15 \\
\hline $\mathrm{O}_{2}$ & 3 & 1,6 \\
\hline $\mathrm{CO}_{2}$ & 2 & 0 \\
\hline $\mathrm{H}_{2} \mathrm{O}$ & 3 & 0 \\
\hline
\end{tabular}

\section{Initial and boundary conditions for kinetic calculation}

Fuel injection began at $-15^{\circ}$ BTDC and the injection ended $6^{\circ}$ ATDC. The calculation was made with the interval of $0.0038 \mathrm{~s}$.
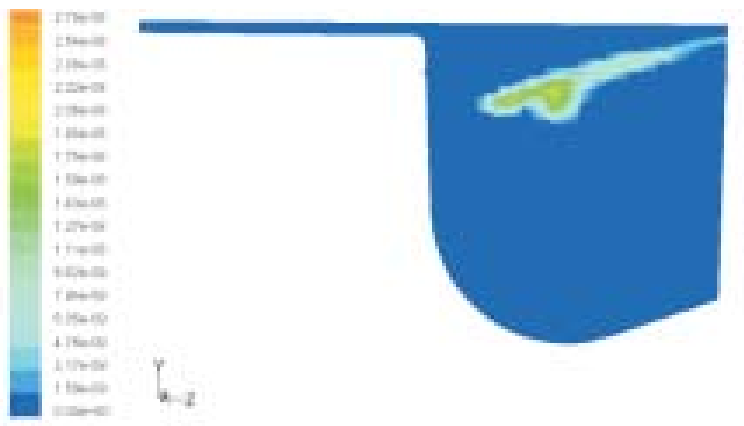

Fig. 29 Droplets of ethanol $(\mathrm{kg} / \mathrm{s})-10^{\circ} \mathrm{CA}$ before TDC, kinetic model

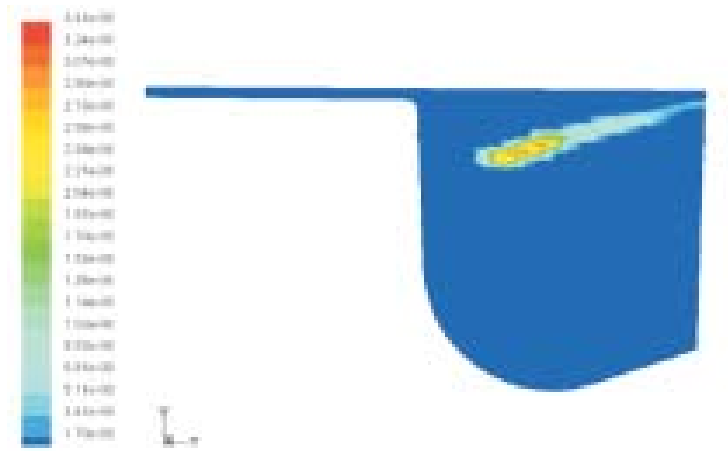

Fig. 31 Droplets of ethanol $0^{\circ} \mathrm{CA}$ before TDC, kinetic model

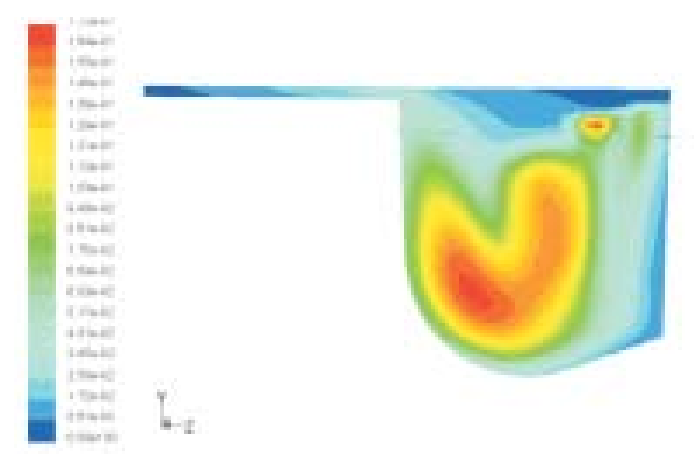

Fig. 33 Mass fraction of $\mathrm{CO}_{2},-10^{\circ} \mathrm{CA}$ before TDC, kinetic model
With the purpose of the model simplification the diesel fuel was substituted by ethanol. The injector drill diameter $d=0.27 \mathrm{~mm}$. The interval of injection timing was $21^{\circ} \mathrm{CA}$. The wall temperature in combustion chamber $T_{s}=700 \mathrm{~K}$. The velocity of ethanol flow through the injection drill $v_{p}=229 \mathrm{~m} \cdot \mathrm{s}^{-1}$. For more precise calculation it was convenient to apply a kinetic model with the detailed description of ethanol transformation through the intermediate products in $\mathrm{CO}$ and subsequently in $\mathrm{CO}_{2}$. For simple chemical reaction $\mathrm{C}_{2} \mathrm{H}_{5} \mathrm{OH}+3 \mathrm{O}_{2}=2 \mathrm{CO}+3 \mathrm{CO}_{2}$ for volumetric reaction is preexponential factor $A=8.435 \cdot 10^{9}$, activation energy $E=1.256 .10^{8}$ $\mathrm{J} . \mathrm{kg}^{-1} \cdot \mathrm{mol}^{-1}$, - termless backward reaction, - thermal conductivity $=0.0454 \mathrm{~W} \cdot \mathrm{m}^{-1} \cdot \mathrm{K}^{-1},-$ dynamic viscosity $\mu=1.72 .10^{-5}$ $\mathrm{kg} \cdot \mathrm{m}^{-1} \cdot \mathrm{s}^{-1},-$ mass diffusivity $D=2.88 \cdot 10^{-5} \mathrm{~m}^{2} . \mathrm{s}^{-1},-c_{p}=1000$ $\mathrm{J}_{\mathrm{kg}} \mathrm{kg}^{-1} \cdot \mathrm{K}^{-1}$, - Sauter mean diameter $S M D=40 \mu \mathrm{m}$, the tempera-

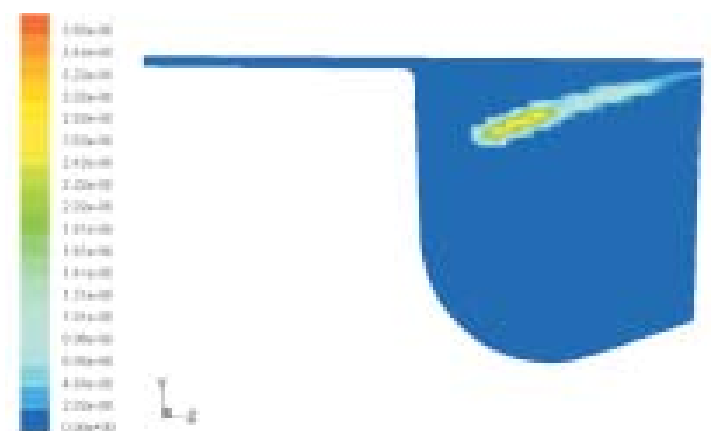

Fig. 30 Droplets of ethanol $-5^{\circ} \mathrm{CA}$ before TDC, kinetic model

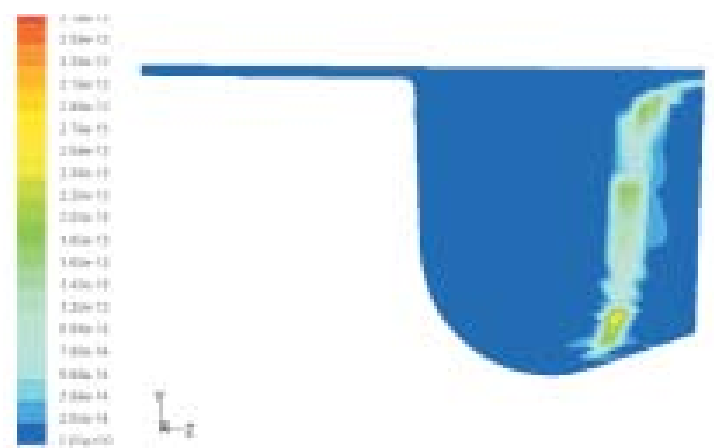

Fig. 32 Droplets of ethanol $5^{\circ} \mathrm{CA}$ after TDC, kinetic model

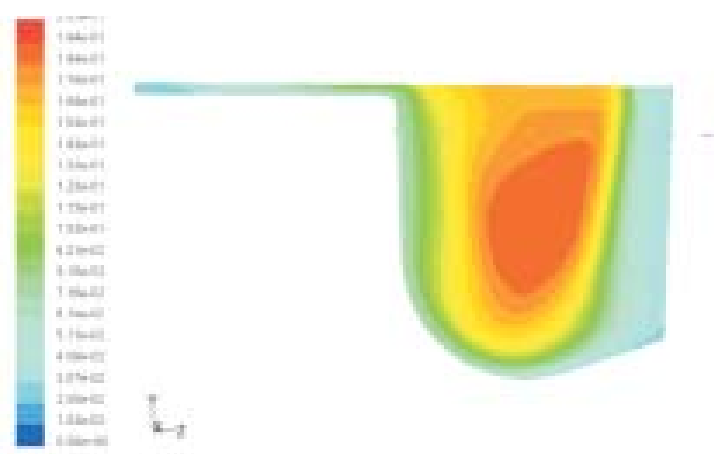

Fig. 34 Mass fraction of $\mathrm{CO}_{2},-5^{\circ} \mathrm{CA}$ before TDC, kinetic model 

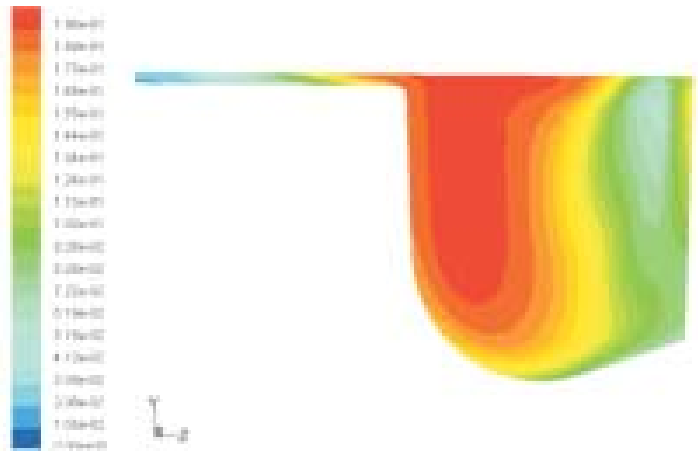

Fig. 35 Mass fraction of $\mathrm{CO}_{2}, 0^{\circ} \mathrm{CA}$ after TDC, kinetic model

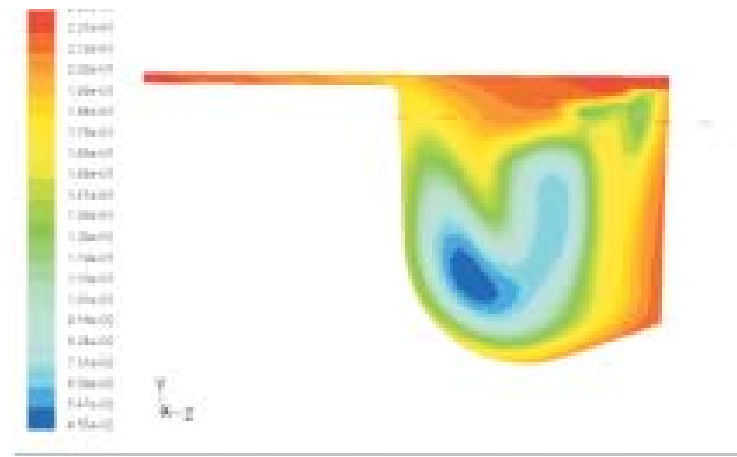

Fig. 37 Mass fraction of $\mathrm{O}_{2},-10^{\circ} \mathrm{CA}$ before TDC, kinetic model

ture of injected ethanol $T_{P}=353 \mathrm{~K}$, the ethanol rate of flow 0.067 $\mathrm{kg} / \mathrm{cycl}$.

\section{Figures of the simulated velocity and concentration fields for kinetic calculation}

Figs. 29 - 32 illustrate mass flow of liquid ethanol in dependence on time through a drill diameter to the right section of the piston. Fuel injection began $10^{\circ}$ before TDC. Spray of fuel starts

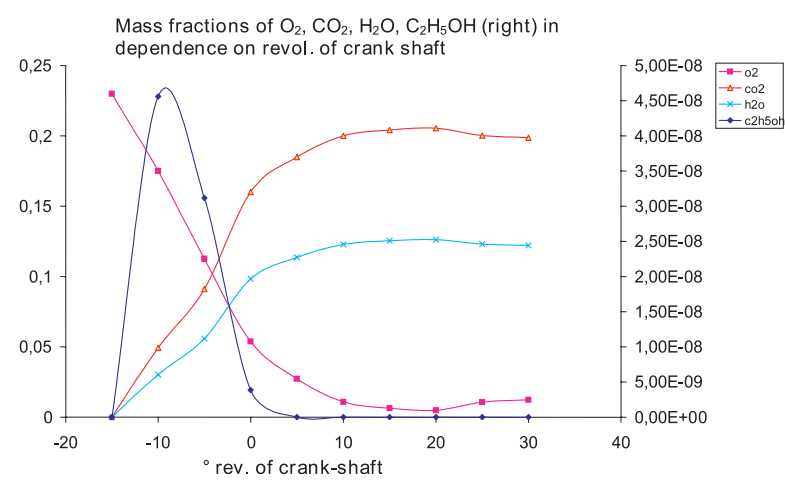

Fig. 39 Mass fractions of $\mathrm{O}_{2}, \mathrm{CO}_{2}, \mathrm{H}_{2} \mathrm{O}, \mathrm{C}_{2} \mathrm{H}_{5} \mathrm{OH}$ (right) in dependence on revol. of crank shaft
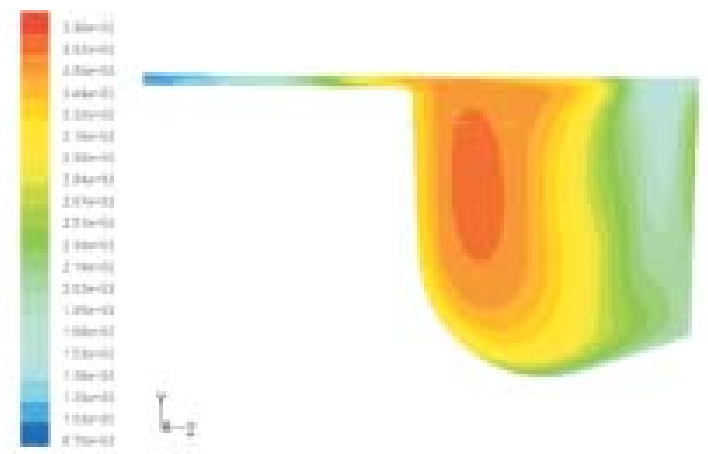

Fig. 36 Temperature $K, 0^{\circ} C A$ after $T D C$, kinetic model

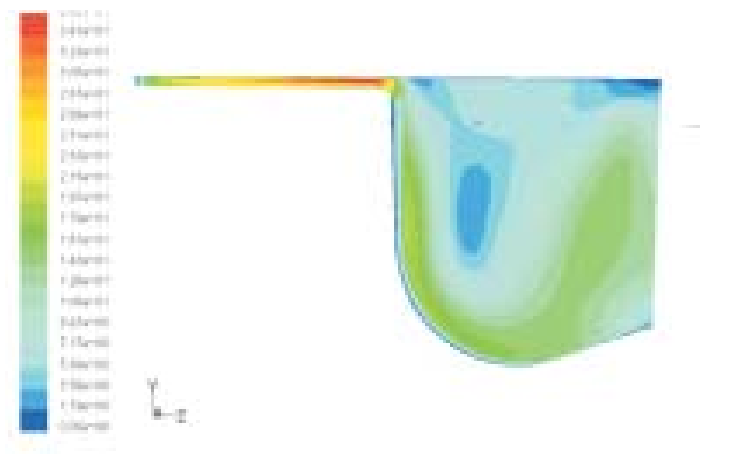

Fig. 38 Iso-tacheo-curves - $10^{\circ} \mathrm{CA}$ before TDC, kinetic model

to deformate due to radial flow, it dependents on Reynolds number of flow. Out flow velocity is too low for ethanol to impact to the wall of combustion chamber.

Figs. 33 - 39 illustrate high-speed transformation of ethanol to carbon dioxid. Flow analysis shows the necessity of modification of time injection of fuel so that the hard combustion of ethanol is lowered. Complicated kinetic model can not be used for inconvenient computer of dynamic calculation.

\section{Conclusion}

The impact of ethanol on exhaust emission composition was simulated using the values of pressure from the real combustion process with pure diesel fuel, ethanol added in diesel and ethanol injected in the suction manifold. The results of $\mathrm{CO}$ concentration show its decrease in the combustion chamber at the adding of ethanol into diesel and its increase at the injection of ethanol in the suction manifold when compared with the results calculated for pure diesel. At present the engine bench test is prepared for validation of the calculated results.

\section{Acknowledgement}

The financial support from the Science \& Technology Assistance Agency, grant 20-014702 is greatly acknowledged. 


\section{KOMNIIKOCle}

\section{References}

[1] ARAI M., TABATA M., HIROYASU, H.: Desintegrating process and spray characterization of fuel jet injected by a diesel nozzle. SAE Paper 840275

[2] HIROYASU H., KADOTA T., ARAI, M.: Fuel spray characterization in diesel engines. Symposium on Combustion Modelling in Reciprocating Engines, Michigan 1978.

[3] HALSTEAD M. P., KIRSCH L. J., QUINN, C. P.: The Autoignition of Hydrocarbon Fuels at High Temperatures and Pressures-Fitting a Mathematical Model, Combustion and Flame, 30, 1977.

[4] HENEIN N. A.: Combustion and emission formation in fuel sprays injected in swirling air, SAE Paper 710220.

[5] VARDE K. S., POPA D., VARDE L. K.: Spray angle and atomization in diesel sprays. SAE Paper 841055.

[6] Fluent Inc. software manual.

[6] BRATSKY, D., LABAJ, J., STACHO, D.: Impact of Ethanol Addition in Diesel on Power Output and Exhaust Emission Characteristics, 5th International Colloquium, Fuels, Technische Akademie Esslingen Proceedings 2005, pp. 31-42, ISBN-Nr. 3-924813-59-0. 